\title{
A orientação argumentativa em textos multimodais: a intertextualidade como critério de análise
}

\author{
Bruno Huann da Silva Nogueira ${ }^{\mathrm{i}}$ \\ Thaís Ludmila da Silva Ranieri ${ }^{\text {ii }}$
}

\section{RESUMO}

Este trabalho propõe uma conexão teórica entre os postulados da Linguística Textual, da Multimodalidade e da Análise da Argumentação no Discurso (CAVALCANTE, 2016; MACEDO, 2018; KRESS e VAN LEEUWEN, 2006). Desse modo, nosso foco é mostrar como a categoria textual de intertextualidade pode indicar uma orientação argumentativa em charges (AMOSSY, 2011 e CARVALHO, 2018). Para esta investigação, contamos com duas charges selecionadas do jornal virtual O Tempo. Os resultados corroboram que essa categoria é útil para se perceber a orientação argumentativa e também apontam que a multimodalidade é um importante elemento na condução dessa orientação.

Palavras-chave: Intertextualidade; Orientação argumentativa; Aspectos multimodais.

\begin{abstract}
This work proposes a theoretical connection between the postulates of Textual Linguistics, Multimodality and Argumentation Analysis in Discourse (CAVALCANTE, 2016; MACEDO, 2018; KRESS and VAN LEEUWEN, 2006). Thereby, our focus is to show how the textual category of intertextuality can indicate an argumentative orientation in cartoons (AMOSSY, 2011 and CARVALHO, 2018). For this investigation, we have selected two cartoons from the virtual newspaper $\mathrm{O}$ Tempo. The results corroborate that this category is useful to understand the argumentative orientation and they also point out that multimodality is an important element in the conduction of this argumentative orientation.
\end{abstract}

Keywords: Intertextuality; Argumentative orientation; Multimodal aspects.

\footnotetext{
${ }^{i}$ Mestrando em Linguística pela Universidade Federal de Pernambuco (UFPE) e Graduado em Letras Universidade Federal Rural de Pernambuco (UFRPE). ORCID: https://orcid.org/0000-0002-8316-5008 | Bruno.letras22@gmail.com

ii Doutora em Linguística pela Universidade Federal de Pernambuco e Professora Adjunta do Departamento de Educação da Universidade Federal Rural de Pernambuco. ORCID: https://orcid.org/0000-0002-5850-6130| thaisranieri@yahoo.com.br
} 


\section{INTRODUÇÃO}

A argumentação e a multimodalidade são elementos que fazem parte de todas as atividades de linguagem. Seja em ambientes mais formais ou, simplesmente, em conversas cotidianas, é possível perceber traços da argumentação, em paralelo aos aspectos multimodais, pois como bem ressalta Elias (2016, p. 191): “os eventos linguísticos não são a reunião de vários atos individuais e independentes, mas uma atividade que se faz com outros, conjuntamente". Nesse cenário, este artigo se propõe a investigar como o parâmetro de análise da intertextualidade, que está situado no escopo da linguística textual, pode evidenciar a orientação argumentativa em charges. Para isso, a arquitetura teórica deste trabalho está assentada nas premissas da análise argumentativa do discurso (AAD), da linguística textual (LT) e da multimodalidade.

Nesse contexto, este trabalho se alinha às pesquisas que vêm sendo desenvolvidas pelo grupo Protexto (CAVALCANTE, 2016; MACEDO, 2018 e OLIVEIRA, 2020), que consideram profícua a relação entre as teorias citadas. Há, porém, variadas teorias que se ocupam de investigar a argumentação, incluindo a teoria da argumentação na língua, cujo expoente mais representativo é Oswald Ducrot, com a qual a linguística textual tem desenvolvido uma pareceria que resultou em trabalhos relevantes. Contudo, essa perspectiva teórica da argumentação restringe o seu campo de investigação às estruturas linguísticas, o que, para o trabalho que ora propomos, seria inviável. A análise argumentativa do discurso, por sua vez, compartilha mais características com a linguística textual como, por exemplo, a importância que é dada ao gênero textual/discursivo na análise, e os aspectos de natureza sociodiscursiva e contextual, o que permite mais facilmente o entrelace entre essas abordagens.

No escopo da LT, teoria pela qual nos posicionamos neste artigo, a noção de texto é entendida como "abstração de coerência [...] que se consolida no momento em que um texto é sociocognitivamente processado, e é unidade concreta da comunicação social, no sentido de que se trata de um evento singular, com início e fim" (MACEDO, 2018, p. 113). Dessa forma, lidamos com o texto como um objeto permeado por aspectos sociocogntivios e que ocorre num momento de interação.

Atrelado a essas premissas, outro ponto a ser tratado aqui é a noção de contexto. Koch (2009) assinala que há tempos esse componente da teoria era entendido como o 
cotexto, ou seja, esses dois itens se imbricavam. No momento atual da LT já não cabe mais pensar assim. Numa visão mais ampliada, Koch (2009) propõe que o contexto abrange o entorno sócio-histórico-cultural. Em Cavalcante e Custódio-Filho (2010), há um avanço na percepção desse elemento, ao considerar que o contexto é também sociocognitivo. Ao adotar essa visão, assumimos que "o texto emerge de um evento no qual os sujeitos são vistos como agentes sociais que levam em consideração o contexto sociocomunicativo, histórico e cultural para a construção de sentidos" (CAVALCANTE e CUSTÓDIO-FILHO, 2010, p. 58). Por conseguinte, a LT tem, atualmente, o contexto como um dos itens significativos em suas análises.

Em alinhamento com essas premissas, as pesquisas desenvolvidas no âmbito da LT têm pleiteado também o caráter multimodal dos textos (CAVALCANTE e CUSTÓDIO-FILHO, 2010). Esses pesquisadores entendem que o texto não se restringe apenas à materialidade linguística e defendem que ele seja encarado como um elemento de natureza sociocognitiva e também multimodal, haja vista que ele se concretiza a partir da união das variadas semioses que juntas atuam na construção de sentidos. Pensando nisso, cabe dizer que a LT é uma disciplina essencialmente transdisciplinar, pois, desde o seu surgimento, vem realizando enlaces teóricos com outras abordagens como, por exemplo, a pragmática, a sociocognição e, sobretudo a partir da última década, a multimodalidade.

Considerando a proposta de trabalho com o gênero charge, a multimodalidade se torna um dos itens indispensáveis para promover uma reflexão pontual. Diante disso, convém frisar que aderimos à abordagem desenvolvida por Kress e van Leeuwen (2006 [1996]), mais especificamente, ao que foi proposto na Gramática do Design Visual (GDV), uma vez que nela são contemplados aspectos relevantes sobre as linguagens imagética e visual. Em conformidade com esses preceitos, Elias (2016, p. 194) afirma que "a multimodalidade pode ser definida como a coocorrência de vários modos de linguagem (semioses), que se integram na construção de significados em interações sociais [...]". Então, a partir do advento da multimodalidade, passou-se a perceber que a linguagem verbal não era a única modalidade de produção de significado linguístico, embora por muito tempo ela tenha ocupado um lugar de privilégio, em detrimento dos outros modos de linguagem. 
$\mathrm{Na}$ esfera de reflexões dessa abordagem, é interessante perceber que Kress e van Leeuwen (2006) partem da gramática sistêmico-funcional, abordagem cujo foco é centrado apenas na linguagem verbal, e desenvolvem uma proposta teórica sobre o estudo de imagens e elementos visuais. Nesse sentido, a GDV é feita pensando que, assim como a língua, as imagens também apresentam estruturas pelas quais se pode apreender um significado. De modo geral, Kress e van Leeuwen (2006) propõem um estudo com base em metafunções, dentro das quais se encontram componentes como a saliência, a distribuição dos planos, informações novas e informações velhas etc. Dito isso, empreenderemos, a partir do próximo tópico, algumas considerações sobre a argumentação, intertextualidade, charge e multimodalidade.

\section{NUANCES DA ARGUMENTAÇÃO}

A análise da argumentação no discurso, que vem sendo desenvolvida há vinte anos por Ruth Amossy, propõe relacionar os postulados da retórica (clássica e nova) ${ }^{1}$ aos pressupostos analíticos da análise do discurso de linha francesa não materialista. Nesse panorama, Macedo (2018, p. 38) salienta que:

\footnotetext{
o intuito de Ruth Amossy, ao propor essa abordagem, é delinear um quadro teórico e metodológico que permita apreender a argumentação (até então negligenciada pelos estudos do discurso) em seus quadros discursivos e institucionais.
}

Via de regra, a argumentação nunca foi um objeto próprio de investigação dentro das análises do discurso, porém a AAD cultiva essa premissa e, também, aspectos de natureza sócio-discursiva e contextual. Dessa forma, essa teoria desenvolvida por Amossy:

[...] reivindica uma análise do discurso que considere a interpretação de estratégias persuasivas. Para a autora, verificar a estrutura dos argumentos e os efeitos que as técnicas argumentativas surtem só faz sentido se o fizermos considerando a rede interdiscursiva e o contexto comunicacional em que eles operam. (CAVALCANTE, 2016, p. 116)

Como se pode ver, a AAD, enquanto uma teoria que preconiza a argumentação como uma dimensão intrínseca ao discurso, não limita seus postulados aos pressupostos da retórica (clássica e nova) e, tampouco, utiliza todas as premissas da análise do 
discurso. Essa fusão de abordagens, embora complexa, permite a AAD avançar, sobretudo, em relação à noção de argumentação. Diante disso, Amossy (2011, p. 130) passa a concebê-la como a "tentativa de modificar, de reorientar ou, mais simplesmente, de reforçar, pelos recursos da linguagem, a visão das coisas da parte do alocutário.”

Por esse ângulo, a teoria não se restringe à noção de tese que deve ser aderida pelo auditório, como é defendida pela nova retórica, nem simplesmente à noção de habilidade/arte, como é delineada na retórica clássica. Portanto, a argumentação pode ser estudada em diversos gêneros como, por exemplo, conversas cotidianas, troca de mensagens em aplicativos ou uma palestra expositiva. Em síntese, essa abordagem se caracteriza por ser:

[...] linguageira, comunicacional, dialógica, genérica, estilística e textual. É
linguageira porque não se reduz a uma análise de operações lógicas, ela
recorre também aos artifícios oferecidos pela linguagem, tais como as
escolhas lexicais, os modos de enunciação, o encadeamento de enunciados,
etc. É comunicacional porque a argumentação visa a um auditório e jamais
pode ser dissociada da situação de comunicação. É dialógica porque concebe
"todo discurso como sendo uma reação a um já dito que tem como fim agir
sobre o outro, ao qual ele busca adaptar-se” (MACEDO, 2018, p. 47). É
genérica pois a argumentação está inscrita em um determinado gênero do
discurso que modela a interação. É estilística à medida que a argumentação
possibilita o apelo a figuras e efeitos de estilo. E é textual, pois a
argumentação deve ser analisada no nível de sua construção textual.
(OLIVEIRA, 2020, p. 18)

Tais princípios colaboram para uma visão da argumentação enquanto uma atividade única e de caráter discursivo que se delineia a partir de um interlocutor e de um locutor, no âmbito textual, considerando que essa é a unidade de funcionamento da língua e que ocorre num dado gênero. Nessa esteira de reflexão, a argumentação empregada por uma mãe para repreender seu filho diante de uma atitude ruim é de uma maneira que difere, por exemplo, de uma carta de reclamação escrita por ela. Com relação a isso, Cavalcante (2016, p. 117) afirma que “[...] tanto a situação enunciativa condiciona o sujeito, dando-lhes instruções de produção e interpretação dos atos de linguagem, quanto, por outro lado, o sujeito influencia o contexto de interação, pois realiza escolhas livres [...]". Nessa lógica, a AAD apregoa que há algumas possibilidades e restrições a partir do lugar institucional que o indivíduo ocupa, pois cada prática social emanará um modo diferente de se expressar com a linguagem.

Ao levar em consideração uma vasta gama de gêneros pelos quais se pode apreender a argumentação, a AAD considera também que há gêneros que são mais e 
menos argumentativos e essa diferenciação é tratada como visada argumentativa e dimensão argumentativa. De acordo com Marchon e Oliveira e Silva (2020, p. 415):

\footnotetext{
os textos que são dotados de visada argumentativa são aqueles que se organizam por uma sequência argumentativa dominante [...]. Os demais textos que não são composicionalmente argumentativos apresentam apenas uma dimensão argumentativa.
}

Por exemplo, um representante comercial, ao vender um produto, se valerá de argumentos explícitos que embasam seu ponto de vista sobre o produto; nesse caso, o texto comporta uma visada argumentativa. Já em uma charge, tem-se uma dimensão argumentativa, pois, mesmo não sendo composta estruturalmente com base em uma sequência de argumentos a partir de uma tese, ainda assim há uma intencionalidade por parte de quem a produz. Após esse breve panorama dos aspectos da argumentação sob o viés da $\mathrm{AAD}$, trataremos, no tópico seguinte, um pouco mais da intertextualidade, bem como do gênero charge.

\section{A INTERTEXTUALIDADE E A CHARGE: ALGUNS APONTAMENTOS}

Nesta seção, buscamos promover uma discussão sobre o processo de intertextualidade, cujo aparato teórico está situado no bojo da linguística textual. Defendemos que esse parâmetro analítico é útil para se perceber a orientação argumentativa do texto e ainda buscamos pensar os aspectos intertextuais, multimodais e argumentativos que compõem o gênero charge. Diante disso, convém salientar que a argumentação não é teorizada no bojo da LT, porém, como bem enfatiza Cavalcante (2016, p. 106), a LT é “[...] uma disciplina que sempre, e por diferentes conduções metodológicas, incluiu a argumentação como um pressuposto inegável". Assim, reiteramos a premissa de que não somente as categorias lexicais e sintáticas são úteis para apreender a argumentação, mas também as categorias textuais, conforme apontam os trabalhos de Macedo (2018) e Oliveira (2020).

A intertextualidade é um parâmetro analítico da LT que propõe que todo texto possui uma relação com outros textos existentes, por isso, não existiria um texto totalmente original, uma vez que todos fazem remissão a outros textos. Segundo 
Oliveira (2020), essa premissa repousa sobre os postulados do dialogismo bakhtiniano, em que considera que os enunciados se encontram em relações constantes, ou seja, não há enunciados isolados. Concatenando com essa ideia, Koch (2009, p. 145) estabelece que “[...] a intertextualidade ocorre quando, em um texto, está outro texto (intertexto) anteriormente produzido, que faz parte da memória social de uma coletividade dos interlocutores". Em vista disso, através desse princípio textual, percebemos como os textos dialogam e mantêm relações entre si, bem como em que medida se valem de outros textos.

Assim como Macedo (2018) e Oliveira (2020), alinhamo-nos aos pressupostos traçados por Carvalho (2018) acerca da intertextualidade, pois a pesquisadora trata desse fenômeno textual de uma maneira mais abrangente e entende

\begin{abstract}
[...] esse fenômeno como um recurso textual-discursivo por meio do qual se constrói, reproduz ou transforma o sentido. Admitimos a relação intertextual: i) quando há diálogo entre textos específicos, dado pela inserção de partes de um texto em outro, ou pelas modificações operadas em um texto de modo que se transformou em outro, ou, ainda, quando um texto cumpre a função de comentar outro, casos a que chamamos intertextualidade estrita; e/ou ii) quando não há a retomada de um texto específico, mas se verifica a imitação entre gêneros do discurso ou entre estilos de autores ou quando um texto alude a conteúdos explicitados em textos diversos, situações a que chamamos intertextualidade ampla. (CARVALHO, 2018, p. 18-19)
\end{abstract}

Por essa ótica, a intertextualidade não se restringe aos elementos que compõem o cotexto, embora seja nele onde se verifique a intertextualidade. Corroborando esse raciocínio, Macedo (2018, p. 114) frisa que "[...] a intertextualidade é um fenômeno identificável na superfície textual, passível de ser evidenciado, mesmo quando a fonte corresponde a um conjunto disperso de textos [...]". Posto assim, ao ampliar o que já se propunha em Koch (2009), a pesquisa de Carvalho (2018) admite que a intertextualidade ocorre na relação entre textos, estilos, temáticas e gêneros semelhantes. Nessa linha de pensamento, Carvalho (2018) estipula também uma proposta classificatória que divide as intertextualidades em estritas e amplas, como vemos abaixo no esquema: 


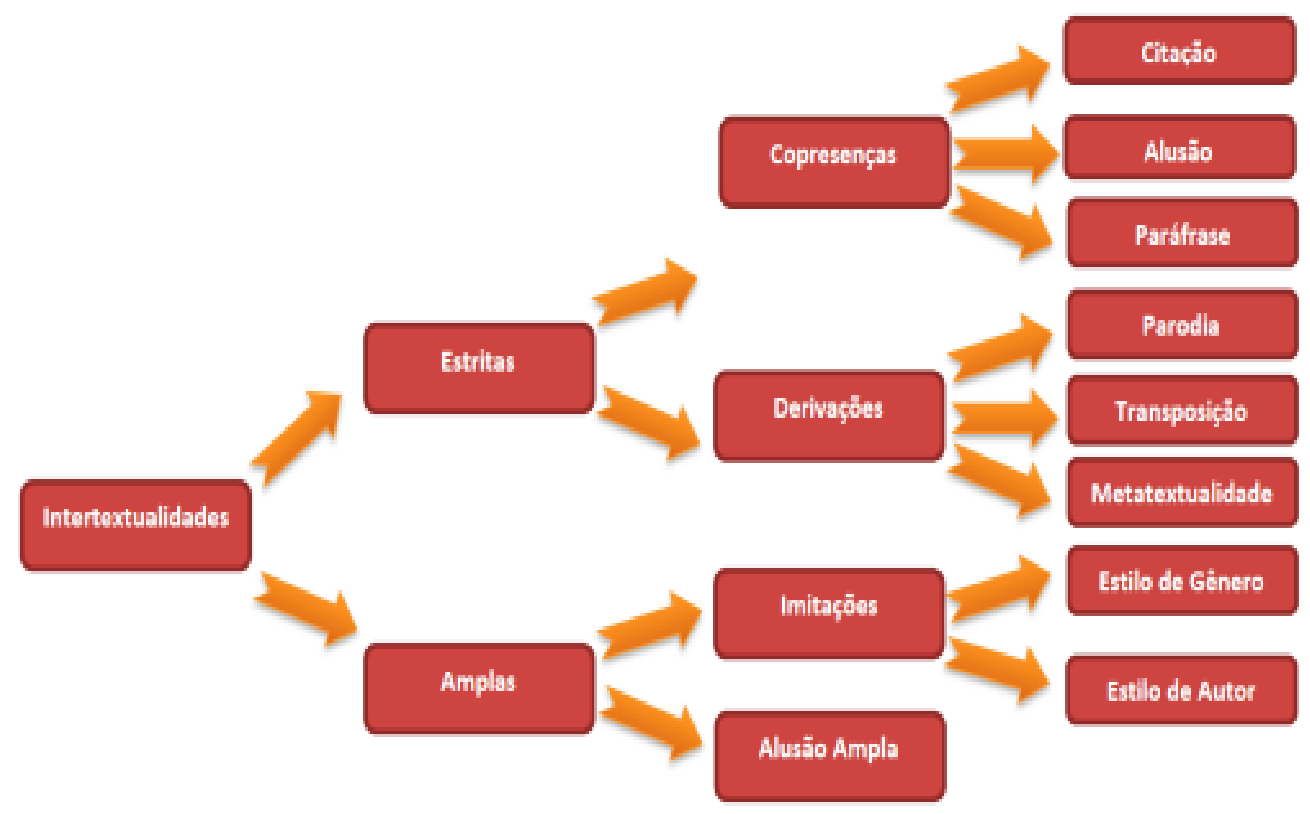

Fonte: Carvalho (2018, p. 110).

Nessas circunstâncias, têm-se as intertextualidades estritas que dizem respeito aos processos intertextuais em que a remissão a um ou uns texto (s) fonte (s) é/são feita (s) de forma precisa. Nessa categoria, são abrangidas as intertextualidades estritas pela copresença que ocorre com a inserção do texto fonte, ou seja, o texto original e as derivações que ocorrem quando há uma transformação do texto fonte.

Por sua vez, as intertextualidades amplas se subdividem em imitações que, segundo Carvalho (2018), ocorrem normalmente relacionadas ao estilo do autor ou aos parâmetros do gênero e, por fim, as alusões amplas que não fazem remissão a um texto específico, mas sim a uma gama de textos que abordam uma determinada temática. Desse modo, diferentemente, do que é traçado em Koch (2009) e em outras pesquisas, o trabalho de Carvalho (2018) avança em relação aos pressupostos da intertextualidade, principalmente por considerar também as intertextualidades amplas como um parâmetro importante para se analisar esse fenômeno.

Nessa corrente teórica, Macedo (2018) salienta que há alguns gêneros que são primordialmente intertextuais. Por exemplo, têm-se as charges e memes que necessariamente vinculam seus conteúdos a alguma notícia ou fato de relevância. Macedo (2018, p. 115) advoga ainda que “[...] qualquer texto, ao estabelecer relação implícita ou explícita com outro(s) texto(s), deixa entrever a assunção de um posicionamento a respeito do tema tratado." Para a pesquisadora, qualquer texto que 
utilize esse procedimento objetiva persuadir. Para pensar essas reflexões, vejamos a charge abaixo:

\section{Excerto (1)}

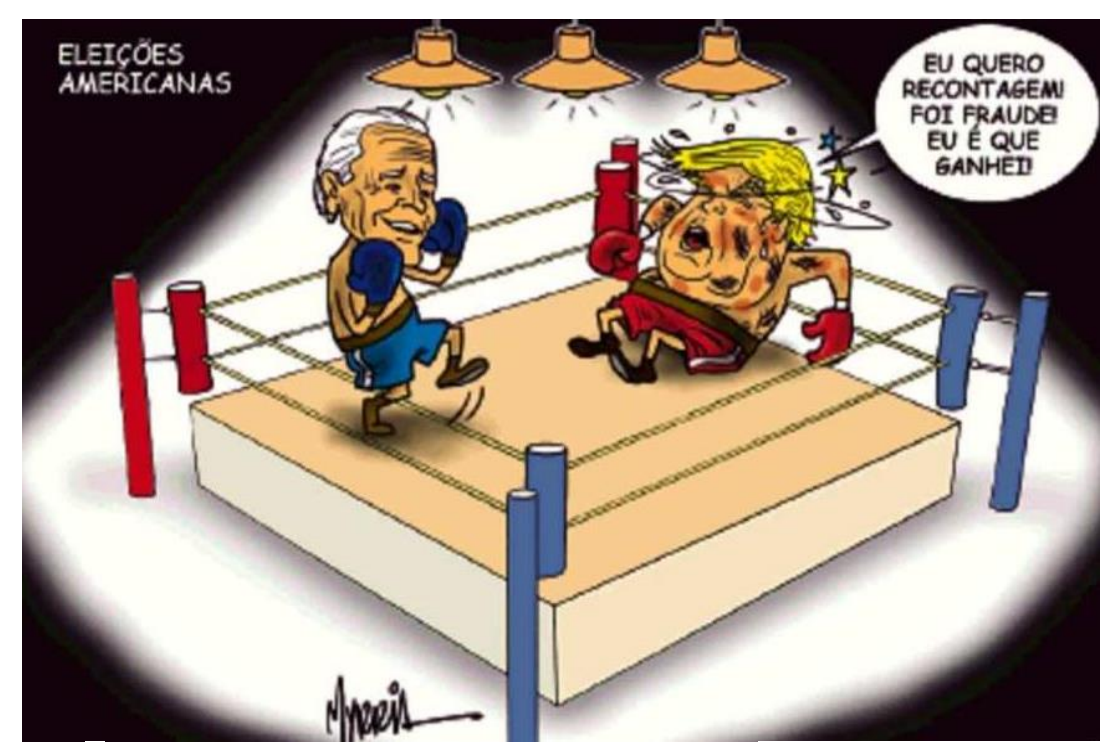

Fonte: <https://www.acritica.com/opinions/07-11-2020> - Acesso em 17/03/2021

Como se pode observar, nesse excerto, a charge trata das eleições americanas ocorridas em 2020, cuja disputa eleitoral tinha como adversários o então presidente Donald Trump e o candidato Joe Biden. Somos situados, nesse contexto, tanto pelos desenhos que promovem a caricatura desses indivíduos quanto pelos elementos verbais. Normalmente, através desse gênero, busca-se representar sujeitos e situações vinculadas a fatos da vida cotidiana. Nesse sentido:

\footnotetext{
Apesar de reconhecermos a autonomia interpretativa da charge, não é possível analisá-la de maneira absolutamente autônoma. Invariavelmente a charge participa de um contexto comunicativo maior que é o jornal, revista ou outro veículo [...] se assenta em intersecções de sentido com a produção verbal, caracterizando-a como uma produção intertextual. (MIANI, 2012, p. 41)
}

Em outras palavras, diríamos que para se interpretar uma charge é preciso ter conhecimentos, ainda que mínimos, sobre o evento que é abordado. Por essa razão, a charge é um gênero primordialmente intertextual. No caso da charge acima, ela se vale de uma metáfora para construir seu objetivo comunicativo, ou seja, propõe-se que a disputa eleitoral equivale a um embate, uma luta de boxe. Ressalta-se ainda que, igualmente a todos os embates esportivos, nesse contexto de disputa presidencial, também há um vencedor, que nesse caso é mostrado como o candidato Joe Biden. A 
intertextualidade emerge aqui não apenas pelo vínculo direto ou indireto com a realidade, mas também com toda a produção linguística (verbal e não verbal) produzida, a partir e sobre esse cenário das eleições americanas.

Nessa estira de reflexão em torno do gênero charge, convém ressaltar dois pontos: sua natureza argumentativa e sua composição multimodal. De modo geral, sabese que as charges expressam a visão dos seus criadores e, por isso, elas possuem uma crítica mais aguçada. Porém, mais do que isso, o poder argumentativo da charge pode intervir em posicionamentos. Em sintonia com isso, Miani (2012, p. 40) aponta a característica da charge "[...] se constituir como instrumento de persuasão, intervindo no processo de definições políticas e ideológicas receptor, através da sedução pelo humor, e criando um sentimento de adesão que pode culminar com um processo de mobilização."

$\mathrm{Na}$ charge acima, por exemplo, somos levados a compartilhar uma visão de pirraça e birra, causada pelo personagem que representa o ex-presidente Trump, diante da situação de derrota. Dessa forma, o leitor é direcionado a pensar que tais atitudes não condizem com a conduta de um presidente, pois são associadas a ações tomadas por crianças; logo, o presidente Trump não seria uma boa escolha.

Além disso, como bem pondera Elias (2016, p. 196),

os procedimentos de decisão, seleção e combinação na constituição do texto envolvem não apenas elementos linguísticos, como também elementos não linguísticos, numa integração de vários modos de linguagem.

No caso das charges, a interpretação perpassa pela compreensão dos elementos imagéticos, ou seja, só codificar a parte verbal (no caso das charges que possuem esse elemento) não garante que se entenderá o sentido da charge. Pensando nisso, assim como todo gênero, a charge apresenta alguns elementos padrões que possibilitam o seu reconhecimento dentro da comunidade que a utiliza. Assim:

\footnotetext{
Quanto aos elementos estéticos e de linguagem constitutivos da charge, como tradicionalmente é apresentada, em desenho, podemos citar a linha, o espaço, o plano, o ponto de enfoque, o volume, a luz e a sombra, o movimento, a narrativa, o balão, a onomatopeia e o texto verbal, não aparecendo, necessariamente, todos estes elementos em todas as charges. (MIANI, 2012, p. 40)
} 
No caso da charge acima, por exemplo, somos apresentados ao conteúdo pela parte verbal localizada no canto esquerdo, muito embora também fosse possível deduzir do que se trata apenas com os elementos imagéticos. Percebe-se que há um enfoque proporcionado pelas cores preto e branco que buscam realçar o fato que é tratado, ou seja, o embate entre os candidatos. Outro ponto de destaque desse embate seria também as cores vermelho e azul presentes nas luvas de boxe, nos shorts dos personagens e nas estacas que se encontram em todas as extremidades do ringue de luta. Essas cores tradicionalmente representam os dois maiores partidos americanos, a saber, republicanos e democratas. Por fim, o desenho representa o candidato Biden como vitorioso e o seu opositor no chão e com ferimentos, o que poderia ser compreendido como uma alusão ao desgaste sofrido por Trump durante as eleições. No seguimento abaixo, lançamos algumas reflexões, buscando relacionar as questões abordadas até aqui.

\section{ANÁLISE DAS CHARGES}

Para pensar as questões tratadas acima, propomos analisar duas charges selecionadas do jornal virtual O Tempo de Minas Gerais. Trata-se de um jornal veiculado na modalidade impressa, mas que já busca atender a uma nova demanda oriunda dos espaços digitais e, para isso, não só disponibiliza uma versão online, como também conta com podcasts e charges publicadas diariamente. Com relação às charges, elas abordam temáticas variadas como política, economia, meio ambiente e esportes, bem como questões específicas da cidade. As duas charges foram coletadas do site do jornal, tratam de questões econômicas e políticas e se situam, pormenorizadamente, no contexto da pandemia de Covid-19.

Essa breve análise busca perceber como a intertextualidade promove a orientação argumentativa, considerando a organização um ponto relevante para essa orientação argumentativa. Propomos, ainda, algumas classificações com base nas proposições teóricas tratadas neste artigo. Buscamos avançar teórica e analiticamente, na medida em que consideramos a intertextualidade um parâmetro passível de se apreender a argumentação. 


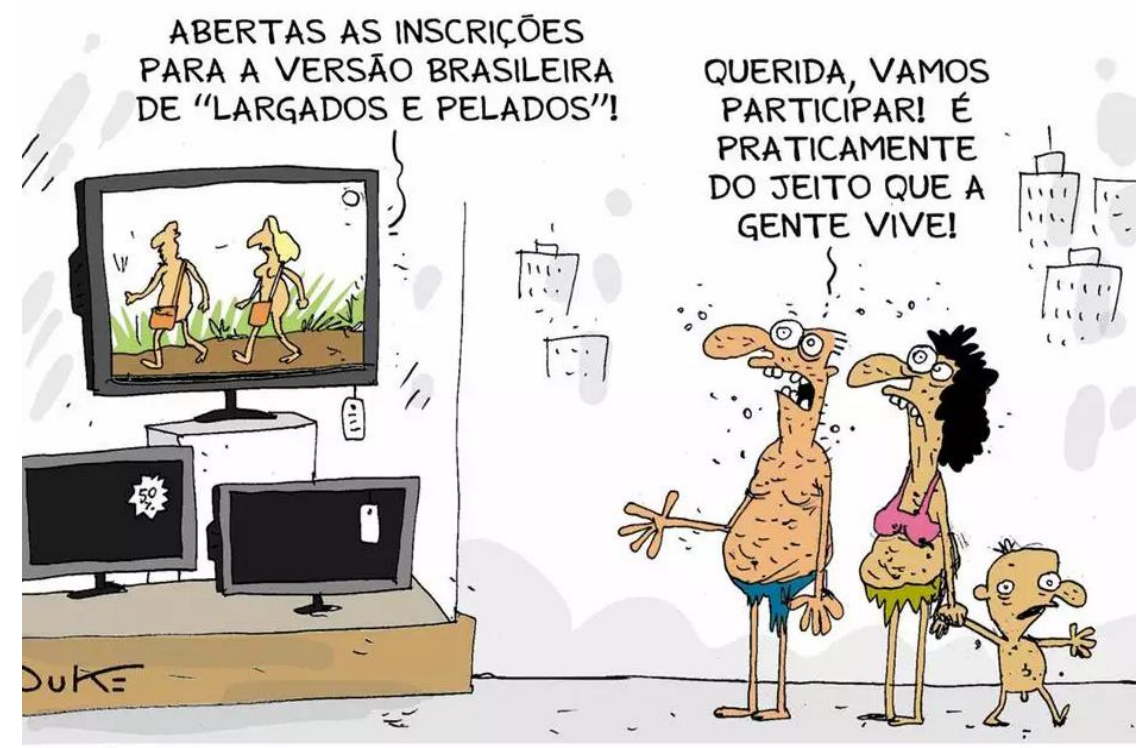

Fonte: https://www.otempo.com.br/charges - Acesso: 10/01/2021.

Como se sabe, a charge mantém um vínculo muito forte com o contexto sóciohistórico-cultural de produção. Pensando nisso, essa charge poderia ser vista a partir de um contexto mais amplo e outro contexto restrito/imediato. No primeiro caso, uma possível leitura menos acurada e, provavelmente, considerando apenas elementos verbais e imagéticos, o interlocutor chegaria à ideia de que a charge trata da desigualdade social $^{2}$ e, de fato, realmente trata. Já numa leitura que considere o contexto imediato, poderíamos pensar ainda que se trata de uma situação, ainda que não ocasionada diretamente, possivelmente intensificada pelo contexto de pandemia.

Essa leitura se dá em razão de haver, neste período político e social de pandemia, um maior distanciamento entre as classes sociais, ou seja, pessoas mais abastadas, por exemplo, não seriam tão afetadas com falta de uma casa para realizar a quarentena, falta de dinheiro para comida e medicamentos e acesso à saúde. É preciso saber, porém, que a charge em questão não direciona especificamente para esse entendimento, embora possamos fazer essa leitura. Dessa maneira, uma pessoa que venha a ler essa charge, no futuro, não fará essa mesma leitura- a menos que saiba que foi produzida nesse contexto- sobretudo, se considerarmos que essa situação de desigualdades sociais é recorrente no Brasil.

No que tange aos aspectos intertextuais, a charge remete a dois fatos, ou seja, dois intertextos. O primeiro fato, que se encontra no plano verbal, diz respeito à nova edição do reality show de origem americana Naked and Afraid, aqui no Brasil 
conhecido como Largados e Pelados. A proposta do programa reside no fato de um grupo de pessoas irem para uma ilha deserta e sobreviverem, nuas por vinte e um dias em condições quase inóspitas. Ainda no plano verbal, o enunciado proferido pelo sujeito “Querida, vamos participar! É praticamente do jeito que a gente vive!” faz uma comparação com a situação a que os participantes do programa são submetidos, o que permite inferir que, para essa família, seria fácil participar do reality show, visto que as condições a que eles seriam submetidos no programa não seriam diferentes daquelas com as quais estariam acostumados na vida real.

O segundo fato, ou o segundo intertexto, trata das mazelas sociais a que os cidadãos estão submetidos, e isto é retratado pela família que reconhece no programa uma situação semelhante à que eles vivem. A intertextualidade ocorre pela representação das disparidades sociais, ou seja, pelos contrastes produzidos pela imagem em que sujeitos são retratados como pessoas em condições de pobreza. A condição social dos indivíduos presentes na charge é reforçada e nos faz manter um vínculo, através da nossa memória social, com todas as produções linguísticas, verbais e imagéticas quando nos deparamos com tal situação.

Nessa linha de pensamento, diríamos, conforme a proposta de Carvalho (2018), que se trata de uma intertextualidade do tipo ampla, pois, como dissemos, apesar de situada no contexto de pandemia, essa situação de desigualdades é recorrente no Brasil; logo, há vários textos-fonte, em diferentes épocas, que funcionariam como intertextos para essa charge, isto é, textos com os quais se poderia estabelecer uma relação de intertextualidade. Além disso, o processo de intertextualidade utilizado nessa charge orienta, e também reforça, a necessidade de se repensar sobre as disparidades sociais. Dessa forma, podemos dizer que, ao chamar atenção para a condição em que essas pessoas vivem, o produtor da charge também sensibiliza o olhar dos interlocutores e se opõe a essa realidade.

Nesse âmbito, percebemos que a charge, diferentemente de outros textos de caráter propriamente argumentativo, não apresenta uma tese de forma explícita. Diríamos, com efeito, que há uma tese que pode se depreender da charge. Com relação a essa possível tese, ela poderia ser entendida como: os sujeitos apresentados na charge são tão pobres que participar do reality show seria fácil, visto que eles estão habituados a uma vida de precariedade. Dessa maneira, apesar de não ser um texto, cuja estrutura 
seja composicionalmente organizada a partir de argumentos, como, por exemplo, o texto dissertativo que é exigido na prova de redação do ENEM, a charge possui uma visada argumentativa. Há uma tentativa de sensibilizar o olhar do interlocutor por meio da charge, ainda que não se estruture com base em argumentos tão óbvios.

Em relação aos elementos multimodais, a charge apresenta dois planos: um, que está situado na parte superior e que basicamente comporta a parte verbal; e o outro, que está abaixo e comporta os elementos imagéticos. Sobre os elementos verbais, percebe-se que há uma tentativa de chamar a atenção do interlocutor, uma vez que as letras apresentam um tamanho grande, considerando as proporções da charge, além de estarem em cor preta, o que as realça mais ainda se levarmos em consideração que o fundo da imagem é branco. Soma-se a isso o fato de nos dois enunciados, presentes na charge, aparecerem pontos de exclamação, os quais podem indicar que em ambos os enunciados os personagens da charge queriam mostrar seus estados emocionais, interjeições, entusiasmo etc.

Por sua vez, os elementos imagéticos constroem a cena de uma família que apresenta condições de escassez de bens materiais, em contraste com um ambiente que evidencia essa escassez, como é o caso da loja de televisões onde eles veem a chamada do programa de reality show, bem como os grandes prédios ao fundo da charge. Outros fatos que tornam notória essa pobreza são as roupas dos personagens que aparentam estar rasgadas, sendo que a criança nem roupa possui, bem como a falta de calçados, pois todos estão descalços na rua. Ademais, o outro fator que chama atenção na composição da charge são as cores utilizadas que, no geral, são cores mais claras, o que nos permite deduzir que o chargista, ao construir essa charge, quis mostrar todo o panorama em volta desses sujeitos, de modo a evidenciar mais ainda a situação de disparidade social.

No tocante aos aspectos propostos na GDV, diríamos que a charge trabalha, assim como propõem Kress e van Leeuwen (2006), com a relação de dado novo e dado velho, no que tange à configuração da imagem. Do lado esquerdo, encontra-se o que os autores chamam de informação já conhecida; e à direita, encontra-se a informação nova e geradora de discussões. De fato, é a partir dos elementos que compõem o lado direito, ou seja, onde se encontram os personagens principais da charge, que se promove uma reflexão acerca da situação a que eles estão submetidos. 
Nesse arcabouço teórico, também somos instigados a pensar sobre a saliência. Esse é um dos componentes da GDV que pressupõe que componentes da imagem mais relevantes ocupam espaços mais significativos no plano imagético. No caso dessa charge, observa-se que a família representeada pelos três indivíduos tem um maior realce na imagem, não apenas pelo tamanho considerável que eles ocupam na imagem, mas, principalmente, pela riqueza de detalhes com que são representados. Nesse sentido, poderíamos supor que o chargista, ao fazer isso, quis chamar atenção dos sujeitos-leitores para esse fato, promovendo, assim, uma reflexão em torno desses personagens. Veremos abaixo a outra charge e, na sequência, sua análise.

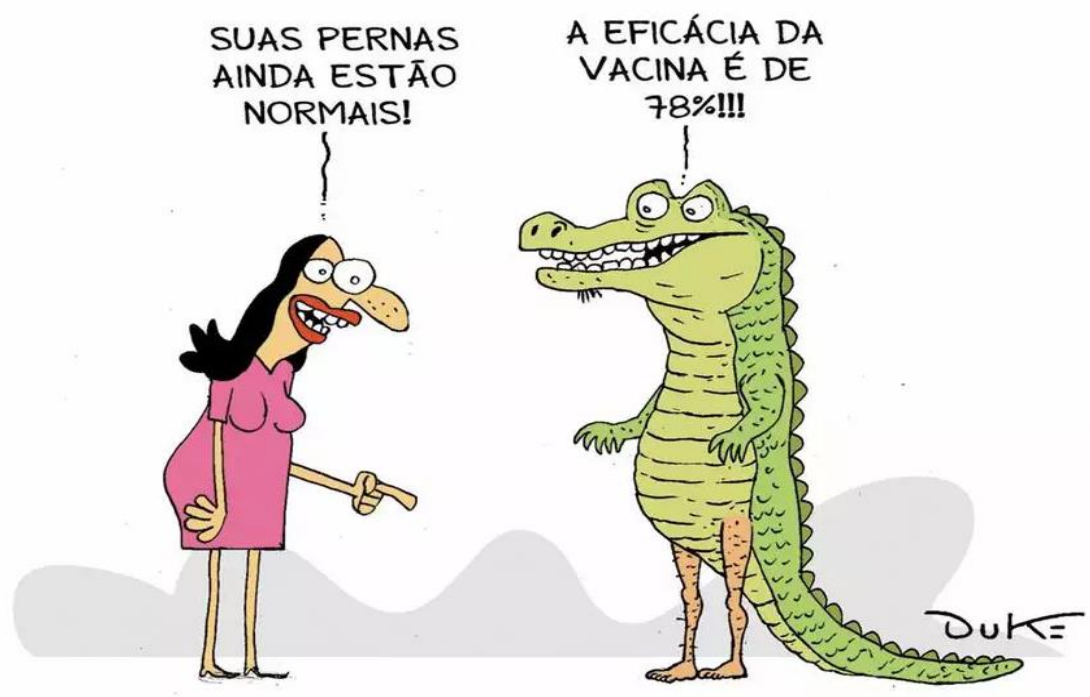

Fonte: https://www.otempo.com.br/charges - Acesso: 10/01/2021.

Assim como na charge anterior, neste exemplo, o contexto sócio-históricocultural também tem um papel crucial na sua compreensão. Nesse cenário, o contexto abrange o momento de produção das vacinas para Covid-19 e aborda, mais especificamente, a dúvida levantada pelo movimento anti-vacina, através do qual se cria na população um sentimento de insegurança em relação às vacinas. Vale ressaltar que, nesse período, o movimento anti-vacina avançou, sobretudo, por meio de notícias falsas que eram veiculadas, principalmente, em espaços virtuais ${ }^{3}$, como as redes sociais; essa disseminação de informações não verídicas objetivava causar temor nas pessoas. Tal como na charge anterior, o interlocutor também é situado, nesse contexto, por meio dos elementos verbais e imagéticos que compõem essa charge. 
Em relação aos aspectos intertextuais, a charge estabelece relação com dois intertextos que circularam recentemente na mídia e que podem ser recuperados se o sujeito-leitor os mobilizar na sua memória social. O primeiro fato/intertexto se encontra no plano verbal e diz respeito à eficácia de $78 \%$ de uma vacina contra Covid-194. O segundo intertexto é apresentado via elementos imagéticos. Trata-se da representação do jacaré que conversa com a mulher. Esse fato remete diretamente à fala do presidente $^{5}$, que, durante uma entrevista, descredibiliza as vacinas que estavam sendo produzidas e sugere a possibilidade de efeitos colaterais, demonstrando uma atitude anti-vacina. Em um dado momento da entrevista, ele suscita como possibilidade de efeitos colaterais a transformação em jacaré de quem se vacinar.

Diante disso, com base nas premissas de Carvalho (2018), podemos dizer que se trata de uma intertextualidade do tipo estrita, uma vez que o intertexto utilizado na charge é facilmente recuperável, ou seja, é possível de se apreender de forma precisa. Nesse arcabouço teórico, diríamos também que é uma intertextualidade estrita do tipo de derivação, tratando-se, nessa situação, de uma paródia, pois o texto-fonte sofre uma releitura cômica na charge, de modo a evidenciar uma crítica ou ironia diante do fato abordado. Em consonância com Macedo (2018), também pensamos que todo tipo de relação intertextual busca orientar um determinado posicionamento sobre uma temática.

Cabe ressaltar que há uma crítica muito sutil que pode não ser percebida, dada a sua tenuidade. Há no Brasil um ditado popular conhecido como "papo de jacaré", que se refere a conversas enganosas e ideias duvidosas; ou seja, quando alguém percebe que se trata de uma conversa não confiável, usa esse termo para se referir a ela. Por esse ângulo, a intenção da charge é mostrar que o enunciado proferido pelo jacaré sobre a eficácia da vacina é duvidoso. Logo, as concepções sobre a eficácia da vacina que a princípio seriam duvidosas, de acordo com uma leitura superficial, passam a não ser se os sujeitos leitores compartilharem dessa memória coletiva que diz que não se deve confiar em "papo de jacaré". Dessa maneira, a orientação argumentativa da charge se alinha a uma visão de que a vacina deve ser recebida e aceita sem hesitação.

Seguindo essa reflexão, o argumento empregado na charge que a priori tentaria defender uma ideia de ineficiência, ao se estabelecer uma relação de equivalência a partir de dois fatos, isto é, as pernas do jacaré e os $78 \%$ de eficácia da vacina contra Covid-19, constitui-se como uma estratégia do chargista para se construir a crítica. 
Igualmente à análise da charge anterior, também defendemos que se pode depreender uma possível tese dessa charge. Pensando nisso, essa possível tese poderia ser entendida como: não se deixe enganar pelo "papo de jacaré". Nesse âmbito, como se pode observar, não se trata de um gênero que predominantemente se vale de argumentos por isso o concebemos como uma dimensão argumentativa, na medida em que influencia de algum modo o leitor.

No que se refere aos aspectos multimodais, essa charge, tal como a anterior, também apresenta dois planos. Em conformidade com os postulados da GDV (2006), identificamos o primeiro como sendo a parte superior, onde está localizada a parte verbal da charge; já na parte inferior, estão fixados os elementos imagéticos. Quanto à parte verbal, notamos aqui também que as letras estão dispostas de modo grande e ressaltadas, visto que sua composição é feita pela cor preta com o fundo branco. Além disso, o ponto de exclamação aparece novamente dando ênfase aos estados emocionais e interjeições dos personagens. Com base nisso, podemos sugerir que essa é uma técnica do chargista que muda a percepção do leitor. Logo, também interfere na maneira como esse leitor vai realizar sua compreensão, ainda que não saibamos se isso é proposital ou não.

Por seu turno, os elementos imagéticos criam uma cena de encontro e diálogo entre dois personagens. Como se pode perceber, há uma surpresa por parte do personagem localizado à direita, em razão das pernas do outro personagem não estarem de acordo com aquilo que se presumiria, ou seja, pernas de jacaré. Esse fato fica evidente pela expressão facial do personagem, como também por estar apontando com o dedo para as pernas do personagem da direita. Outro fator que chama a atenção do interlocutor são as distribuições de cores pela charge. Nesse caso, há um entorno aos personagens quase que totalmente branco, já os personagens são mais coloridos, o que, de certa forma, prende a atenção do leitor. Esse aspecto pode ser considerado também o ponto de saliência dessa charge (KRESS e VAN LEEUWEN, 2006). Não apenas as cores fortes, mas também o tamanho dos personagens, produzem esse efeito de saliência, ou seja, põem em destaque os personagens.

Concatenando com essa ideia, convém pensar ainda sobre a relação entre dado novo e dado velho nos moldes propostos pela GDV. Nesse sentido, do lado esquerdo estaria a informação velha ou mais previsível; nesse caso, tem-se o desenho que 
representa a mulher, bem como o enunciado que é proferido por ela. Já do lado direito, tem-se a parte da charge que seria o dado novo, isto é, a representação do jacaré e, mais do que isso, é ainda a parte que suscita possíveis discussões, principalmente quando se leva em consideração a parte verbal, pertencente à fala do jacaré. Diríamos que é a partir desse lado da charge que o interlocutor é levado a refletir.

No que tange à charge, comungamos da premissa estabelecida por Miani (2012, p. 37) quando a considera "uma modalidade das linguagens iconográficas, de natureza dissertativa e intertextual e que se caracteriza como uma prática discursiva e ideológica." Embora, no senso comum, a charge seja pensada como um gênero que promove entretenimento por meio de uma linguagem que induz ao riso, ela tem um teor crítico e fomenta uma reflexão em torno do tema abordado. Normalmente, utiliza-se de um discurso humorístico, engraçado e, por vezes, através de figuras de linguagem que amenizam ou intensificam uma crítica, situada na parte verbal desse gênero.

Por exemplo, na primeira charge, tem-se uma metáfora e uma possível ironia. A metáfora acontece quando se estabelece a comparação entre a situação dos sujeitos da charge com os participantes do reality show. Ao mesmo tempo, é possível perceber uma sutil ironia, na medida em que os sujeitos demonstram interesse em algo, mas na verdade não é aquilo de que eles precisariam para ter melhores condições de vida. Já na segunda charge, há uma metonímia utilizada, nesse contexto, através do termo "eficácia da vacina", por meio da qual se pode inferir que a utilização dessa vacina condiciona a transformação de pessoas em jacaré. De modo geral, essas figuras de linguagem também norteiam a maneira como o interlocutor interpreta as charges e, por isso, é uma estratégia argumentativa.

Em suma, buscamos pensar como o parâmetro da intertextualidade interfere na orientação argumentativa, a partir do gênero charge, como corrobora Miani (2012, p. 42): "na sua natureza intertextual, a charge pode estabelecer, em relação aos demais textos, uma posição convergente ou divergente." Nas observações feitas, constatamos que a orientação argumentativa se opunha aos fatos pleiteados nas charges. Com isso, saímos da visão que considera argumentação apenas no plano linguístico, ou seja, passível de ser identificada, exclusivamente, a partir de categorias lexicais e sintáticas da língua e passamos a entender que a linguística de texto com o seu suporte teórico muito tem a nos revelar. 
É interessante notar que a linguística de texto é uma disciplina essencialmente transdisciplinar e que faz conexões teóricas com outras abordagens, a fim de enriquecer o seu programa teórico e analítico. Como bem lembra Elias (2016, p. 197): “no campo atual dos estudos do texto, a noção de multimodalidade se faz presente em análises e discussões propostas [...]." Diante disso, nossa breve análise também se ocupou em mostrar como a organização dos elementos multimodais na charge interfere e condiciona a leitura do interlocutor. Nessa reflexão, propomos que os aspectos multimodais e argumentativos atuam juntos, promovendo o sentido nas mais variadas atividades de linguagem.

\section{CONSIDERAÇÕES FINAIS}

Em vista das reflexões empreendidas neste artigo, objetivamos mostrar que a categoria analítica da Intertextualidade, presente nos estudos da linguística textual, pode ser utilizada como critério de análise para se perceber a mobilização da argumentação em charges. Para tanto, assumimos como frutífera a relação entre a LT, a AAD e a multimodalidade, por meio da qual desenvolvemos nossa análise. Nessa lógica, nos afastamos de trabalhos que se debruçam sobre a argumentação apenas no plano verbal, uma vez que consideramos que todos os textos apresentam em certa medida uma orientação argumentativa e aspectos multimodais (AMOSSY, 2011; CAVALCANTE, 2016 e ELIAS, 2016).

Em sintonia com essas proposições, nossa análise mostrou que, por meio da intertextualidade, é possível sinalizar uma possível orientação argumentativa. Ademais, percebemos ainda que a organização dos modos de linguagem influencia na maneira como o interlocutor construirá o sentido da charge. Dessa maneira, pleiteamos a ideia de que o aparato teórico dos estudos textuais pode e deve ser utilizado como princípio para se perceber a orientação argumentativa. Embora o modus operandi desse artigo tenha realçado o parâmetro da intertextualidade, cremos que outras categorias analíticas da LT também podem ser úteis nessa empreitada. 


\section{Referências}

AMOSSY, Ruth. Argumentação e Análise do Discurso: perspectivas teóricas e recortes disciplinares. Trad. Eduardo Lopes Piris e Moisés Olímpio-Ferreira. EID\&A - Revista Eletrônica de Estudos Integrados em Discurso e Argumentação, Ilhéus, n. 1, p. 129144, jun./nov. 2011

Contexto, 2018.

A argumentação no discurso. Trad. Eduardo Lopes Piris et al. São Paulo:

CARVAlHO, Ana Paula. Sobre intertextualidades estritas e amplas. 136f. - Tese (Doutorado em Linguística). Universidade Federal do Ceará, Fortaleza, 2018.

CAVALCANTE, Mônica. Abordagens da argumentação nos estudos de Linguística Textual. ReVEL, edição especial vol. 14, p. 106-124, 2016.

CAVALCANTE, Mônica; CUSTÓDIO FILHO, Valdinar. Revisitando o estatuto do texto. Revista do GELNE, Piauí, v.12, n.2, 2010.

ELIAS, Vanda. Estudos do texto, multimodalidade e argumentação: perspectivas. ReVEL, edição especial vol. 14, n. 12, 2016.

KOCH, Ingedore. Introdução a Linguística Textual. $2^{\mathrm{a}}$ Ed. São Paulo: Editora WMF Martins Fontes, 2009.

KRESS, Gunther; VAN LEEUWEN, Theo. Reading Images: The Grammar of Visual Design. London: Routledge, 2006 [1996].

MACEDO, Patrícia. Análise da argumentação no discurso: uma perspectiva textual. 245f - Tese (Doutorado em Linguística). Universidade Federal do Ceará, Fortaleza, 2018.

MARCHON, Amanda; OLIVEIRA, Rafael; SILVA, Welton. Argumentação: da retórica à linguística do discurso. In: LIMA, Alisson; SOARES, Maria; CAVALCANTE, Sávio. Linguística Geral: os conceitos que todos precisam saber. São Paulo: Pimenta Cultural, 2020. p. 394-420.

MIANI, Rozinaldo. Charge: uma prática discursiva e ideológica. Nona Arte: Revista Brasileira de Pesquisas em Histórias em Quadrinhos, v. 1, p. 37-48, 2012.

OLIVEIRA, Rafael. Uma análise textual do pathos em polêmicas. 2020. 144f Dissertação (Mestrado em Linguística) - Universidade Federal do Ceará, Fortaleza, 2020 . 
${ }^{1}$ Devido ao espaço deste artigo e também por questões de escolha teórica, optamos por não tratar da retórica (clássica e nova), mesmo sabendo que ela é um ponto importante dentro da análise argumentativa no discurso.

2 Link da notícia que ratifica o aumento das desigualdades na pandemia: $<$ https://portal.fiocruz.br/noticia/desigualdade-social-e-economica-em-tempos-de-covid-19 > Acesso em: $17 / 03 / 2021$.

${ }^{3}$ Link da notícia que trata da expansão do movimento anti-vacina:

<https:// www.uol.com.br/vivabem/noticias/redacao/2020/10/29/movimento-antivacina-avanca-onlinepor-que-ele-e-ameaca-a-saude-publica.htm> - Acesso em: 17/ 03/ 2021.

${ }^{4}$ Link da notícia que trata da eficácia da vacina: <https://www.uol.com.br/vivabem/noticias/agenciaestado/2021/01/09/eficacia-de-78-da-vacina-e-de-parte-do-estudo-diz-cientista.htm> - Acesso em: 17/ 03/ 2021.

${ }^{5}$ Link do vídeo: <https://www.youtube.com/watch?v=lBCXkVOEH-8> - Acesso em: 11/01/2021. 